\title{
INTERFACES ENTRE A POESIA ÉPICA, O ROMANCE E O ROMANCEIRO EM PARATEXTOS DO SÉCULO XIX
}

\section{INTERFACES BETWEEN EPIC POETRY, ROMANCE AND THE HISPANIC BALLAD IN 19TH CENTURY PARATEXTS}

\author{
Marcos Machado Nunes ${ }^{1}$
}

\begin{abstract}
Resumo: Nos começos do Romantismo, o romance, no sentido de poema narrativo longo de matriz medieval, será tomado como modelo para a renovação literária. Contudo, ainda que o foco das atenções recaia sobre o romance, que na Península é relacionado à tradição local do romanceiro (as "baladas ibéricas"), o gênero épico será mantido no horizonte. O trabalho procura demonstrar como, expressando intenções de filiação de gênero, mas também constituindo e negociando posições para autores e obras no campo literário, os paratextos de poemas narrativos longos refletem essa situação.
\end{abstract}

Palavras-chave: poesia épica, Romantismo, romance, paratexto, literatura portuguesa, literatura brasileira

\begin{abstract}
In the early years of Romanticism, romance, the long narrative poem of medieval origins, is taken as a model for literary inovation. However, though romance - which in the Iberian Peninsula relates to the local tradition of the hispanic ballad - is in the spotlight, epic poetry would be kept in the horizon. We try to show how paratexts of Portuguese and Brazilian narrative poems, while not only expressing intentions of genre affiliation, but also constructing the work and its author and negotiating a place for them in the literary field, reflect on this situation.
\end{abstract}

Keywords: epic, Romanticism, romance, paratext, Portuguese Literature, Brazilian Literature

O empenho pela afirmação das identidades nacionais e pela constituição dos cânones literários nacionais, assim como as aspirações de transcendência próprios do Romantismo, mantiveram a poesia épica no elenco das suas ambições. Tal fato assegurou uma sobrevida ao gênero ao longo do século XIX, que só seria possível devido às transformações a que ele se sujeitaria. ${ }^{2}$ A relevância da poesia épica não deixou de implicar uma reflexão sobre essa situação, disseminada em diferentes meios: historiografia, imprensa, textos e paratextos, etc. ${ }^{3}$ Este trabalho apresenta um aspecto dessa reflexão no âmbito dos paratextos (mais

\footnotetext{
${ }^{1}$ Ruhr-Universität Bochum - RUB, Bochum, Alemanha; https://orcid.org/0000-0001-8441-6668;

Marcos.MachadoNunes@ruhr-uni-bochum.de

${ }^{2}$ A esse respeito, quanto ao espaço iberorromânico, ver os trabalhos do projeto "A poesia épica sob as condições estético-literárias do Romantismo", desenvolvido em Bochum sob coordenação de Roger Friedlein (https://homepage.ruhr-uni-bochum.de/roger.friedlein/epos_index.html).

${ }^{3}$ Esta reflexão tem sido objeto de um projeto conjunto da Ruhr-Universität Bochum e da UFRGS, desenvolvido no âmbito do Probral (DAAD e Capes) com coordenação de Roger Friedlein e Regina Zilberman (https://homepage.ruhr-uni-bochum.de/roger.friedlein/probral_pt.html).
} 
especificamente, dos prefácios, eventualmente associados a notas e subtítulos) de poemas pioneiros do Romantismo português, com breve incursão por um caso brasileiro. Trata-se da referência ao romance (no sentido de narrativa longa em verso com representação idealizante da moral cortês e ênfase na aventura e no maravilhoso) como paradigma da inovação poética em geral e do poema narrativo em particular. No que concerne Portugal, observamos que em dois dos autores estudados - Almeida Garrett (1799-1854) e José Maria da Costa e Silva (17881854) - está implícita a exploração do que J. M. Schaeffer (2002, documento eletrônico) apresenta como os diferentes caminhos do termo "romance" nos diferentes espaços culturais europeus: na Península Ibérica, o termo viria a designar a "balada ibérica", uma poesia narrativa de matriz popular com transmissão em grande medida dependente de contextos orais e traços formais característicos (uso da redondilha e rima assonante única ao longo de todo o poema). No sentido de "balada ibérica", o romance costuma figurar nas antologias nomeadas "romanceiros", termo que, para fins de desambiguação, utilizaremos para referir este sentido de "romance".

No primeiro sentido indicado, de poema narrativo longo, o romance surge na França medieval sob influência da canção de gesta e da lírica trovadoresca. O termo "romance" deriva do latim "romanus", "cidadão romano" ou, por extensão, a partir de um certo momento, "cidadão do Império"; passando pela forma adjetiva "romanici" e sua derivada adverbial "romanice", chegamos a "romanz", forma que, no francês antigo, qualifica a matéria expressa nas línguas já diferenciadas do latim, significando "em língua de origem romana" (Stierle, 2010, p. 55-56). O termo passa a nomear o poema narrativo longo quando, na França, já no século XII, se começa a "mettre en romanz", "pôr em vernáculo", matéria literária que circulava em outros idiomas, sobretudo o latim. ${ }^{4}$ Em torno a essa prática, e com textos já cunhados no novo idioma a partir do material literário oral e escrito, cria-se uma tradição literária da poesia narrativa que será conhecida como "romance", cujos cânones são facilmente identificados: deslocamento do núcleo temático heróico do combate para a aventura e, em particular, a busca, que chega a receber dimensão espiritual; peripécias constantes; importância dos afetos para a cadeia de acontecimentos, em especial o amor cortês e sua codificação; maravilhoso baseado em antigas lendas e mitologia, apelando à imaginação do leitor e criando, como observou Schaeffer (2002, documento eletrônico), um "contra-modelo da realidade em que vive o leitor". ${ }^{5} \mathrm{O}$ gênero medieval deixará uma herança profunda na literatura europeia, tendo uma sobrevida de longa duração, ora com maior, ora com menor evidência. O Romantismo, como a própria etimologia da palavra que nomeia o conjunto de tendências estético-literárias (entre outras) que recebe este nome ${ }^{6}$ já deixa transparecer, buscará no romance os fundamentos de sua poética e sua cosmovisão, para além do âmbito do poema narrativo: valorização da imaginação, dos afetos e do sonho, busca da transcendência à realidade cotidiana, revelação visionária e encantamento do mundo, viagem e errância, busca do desconhecido e do ideal. Isso ocorreria, num primeiro momento, de uma maneira bastante explícita e direta, sobretudo na Inglaterra, com a publicação de antigos romances em antologias de poesia popular, em conexão direta com a reação à estética neoclássica e a emergência do medievalismo romântico. ${ }^{7}$

\footnotetext{
${ }^{4}$ Sobre a emergência das línguas neolatinas na escrita. ver Bensimon; Darbord; Gomez-Geraud, 2015.

${ }^{5}$ Naturalmente, essa matriz temática (no todo ou em parte) pode ser encontrada em outros contextos literários, com ou sem relação com a base medieval europeia aqui referida. Sobre o romance e suas matrizes temáticas (geralmente referidas como "o romanesco", termo que também costuma ser empregado para desambiguação com o romance moderno, em prosa e com abordagem realista) numa perspectiva trans-histórica, Frye (1957), Jameson (1981), Schaeffer (2002), Declercq e Murat (2004) e Schöneich (2007).

"A bibliografia sobre a etimologia de "Romantismo" é extensa. O trabalho que parece ser o mais detalhado sobre o tema é o de Stierle (2010).

${ }^{7}$ Essa situação, no contexto inglês, estará associada às reações à Revolução Francesa e às guerras napoleônicas. Portando uma imagem idealizada do passado, mas, ao mesmo tempo, permitindo divisar um mundo de potencialidades e utopia, "romance" será um termo politicamente ambivalente na Inglaterra dos inícios do
} 
Em Portugal, a ambivalência semântica de "romance" (termo que oscilará entre o poema longo medievalizante e a "balada ibérica") permite aos poetas aqui estudados evocar, com o uso do termo nos paratextos, um fundo comum de uma literatura narrativa de raízes medievais. Os prefácios analisados expressam o entendimento implícito de que, embora correspondendo a formas literárias diferenciadas, uma matriz comum poderá ser evocada num movimento de busca das origens tipicamente romântico. Os poemas aqui apresentados se constroem a partir de uma relação arquitextual com o romance medieval e/ou estabelecem uma conexão hipertextual com poemas específicos do "romanceiro". Neste sentido, os paratextos prefaciais, entendidos como instâncias que organizam a comunicação de textos (Kreimeier; Stanizeck, 2004, p. vii), terão uma função decisiva ao explicitar a conexão hipertextual e sublinhar a relação arquitextual aqui indicadas, e, com isso, negociar a posição de autores e obras no campo literário no processo de transformação radical que começa a desencadear-se.

Os paratextos estudados apresentam, basicamente, tentativas de orientação de leitura: intenções de filiação do texto a um gênero literário ou as possibilidades de associação a uma estética (Romantismo e Neoclassicismo), mas também expressam concepções sobre os gêneros em questão, romance/romanceiro e, em menor medida, épico. Cabe salientar que não nos interessa aqui discutir a pertinência daquelas intenções, tampouco a correção dessas concepções: embora trabalhando com paratextos de poemas narrativos longos (em alguns casos inclusive com elementos formais da tradição épica: estrofação, proêmio), não é um pressuposto, nem uma intenção do nosso trabalho a classificação dos textos específicos como épica ou não, como forma de alcançar uma contraprova do discurso dos paratextos. Contudo, como veremos, será importante o contraste entre o texto e discurso paratextual.

A interface entre épica e romanceiro e/ou romance deriva da ênfase dada a este(s) último(s) nas tentativas de inovação poética que marcam a literatura portuguesa nos anos 1820 e 1830 , sob o protagonismo de Almeida Garrett, mas não limitadas a ele. Um pequeno número de autores, hoje pouco conhecidos, que publicou umas poucas obras com as características objeto de nosso trabalho nos anos 1830 e 1840, compartilham com Garrett o mesmo interesse pelo romance e a tradição popular ibérica e o mesmo desejo de renovação literária. Um desses autores, José Maria da Costa e Silva, incluirá a épica nessa equação de uma maneira mais incisiva que os demais. Trata-se de um episódio breve na história literária portuguesa, marcado pela experimentação e pela busca de uma transformação disruptiva, nem sempre exitosa do ponto de vista da qualidade literária dos textos produzidos. Já o caso brasileiro, o poema $A$ nebulosa, de Joaquim Manoel de Macedo (1820-1882) aparecerá incidentalmente, sem maior fôlego analítico, quase como um apêndice.

Após algumas reflexões teóricas sobre o paratexto em geral e o prefácio em particular, trataremos da relação entre romance e poesia popular no prefácio de Adosinda (1828), de Garrett, procurando definir o seu entendimento do gênero e a relação com a inovação literária. Definido esse entendimento, compartilhado em grande medida por Costa e Silva, abordamos o material prefacial de textos que, embora definidos como romances no discurso paratextual, são marcados pela presença de elementos da tradição épica.

\section{O paratexto e o prefácio autoral: autoria, intenção, obra}

É conhecido o esforço de Gérard Genette, ao longo de sua obra, por teorizar a relação do texto literário com a rede textual em que ele se insere e com a qual interage. No seu Seuils, de 1987 (lançado no Brasil sob o título de Paratextos editoriais), Genette se dedicou à análise

Romantismo (Duncan, 1999, p. 682). Para a presença do romance no contexto cultural e literário inglês, cf. Curran, 1986; Duncan,1992; Duff, 1999 e 2009. 
daquilo que caracterizou como um espaço intermediário e periférico, de delimitação entre o dentro e o fora do texto: o paratexto, que ele define como

um certo número de produções, elas mesmas verbais ou não, como um nome de autor, um título, um prefácio, ilustrações, as quais nem sempre se sabe se as devemos considerar como pertencentes a ele [ao texto], mas que em todo caso lhe servem de entorno e prolongamento, precisamente por apresentá-lo, tanto no sentido habitual deste verbo, como no seu sentido mais forte: por fazê-lo presente, por assugurar a sua presença no mundo, sua recepção e sua consumação, sob a forma, hoje ao menos, de um livro (Genette, 1999, p. 7, tradução nossa).

Caracteriza, portanto, o paratexto, para Genette, a indeterminação de seu pertencimento ao texto, sua condição de liminaridade, de espaço de trânsito e intercâmbio entre o dentro e o fora (Wirth, 2004). Será espaço para a voz autoral estabelecer contato com o público e agir sobre ele, preparando a recepção do texto e negociando uma "leitura mais pertinente" (Genette, 1999 , p. 8). O paratexto está diretamente associado à materialidade do texto, sua conversão em mídia impressa e sua circulação: "O paratexto é, portanto, para nós aquilo através do qual um texto se faz livro e se propõe como tal" (Genette, 1999, p. 7-8). Genette investigará no seu estudo os meios, modos e efeitos da ação do autor e/ou seus partidários, a partir das características espaciais (onde?), temporais (quando?), substanciais (como?), pragmáticas (de/a quem?) e funcionais (para quê?) do paratexto, criando, assim, uma tipologia classificatória. As características funcionais seriam as únicas a apresentar variabilidade em função do gênero paratextual.

Neste estudo, analisamos exemplos de um gênero paratextual chamado por Genette como "instância prefacial" ou simplesmente "prefácio": "Nomearei aqui prefácio, por generalização do termo mais frequentemente empregado em francês, toda espécie de texto liminar (preliminar ou pós-liminar), autorial ou alográfico, consistindo em um discurso produzido a propósito do texto que o segue ou precede" (Genette, 1999, p. 164). "Prefácio" designará, assim, independentemente do nome que receberá num livro específico ("prefácio", "posfácio", "prólogo", "advertência", "nota", etc.), o (para)texto liminar, público ou originalmente privado (como as "cartas"), em que a voz do autor ou de um terceiro tenta mediar a recepção do texto. No caso dos prefácios autorais originais (aqueles que acompanham a primeira edição do livro) - e é esse o caso dos prefácios analisados aqui -, a par dessa função mais geral, haveria funções mais específicas, classificadas em dois grupos: as que correspondem aos "temas do por que" e as do "como" (ler o livro). ${ }^{8}$ Exercendo as funções próprias aos "temas do por que", os prefácios procuram afirmar o valor do texto, do tema escolhido e do tratamento a ele atribuído, chamando a atenção, por exemplo, para a sua importância, sua unidade, ou ainda para o modo como o texto inova ou, ao contrário, conserva uma tradição. Já os "temas do como" dão ao prefácio funções específicas cujo objetivo geral seria transmitir informações consideradas relevantes para a leitura, como a gênese do texto, seu título, o público-alvo, o contexto e, importantes para nosso trabalho, as intenções do autor e as tentativas de filiação ou afastamento quanto aos cânones de um gênero literário. ${ }^{9}$

\footnotetext{
${ }^{8}$ Genette, 1999, p. 199-239 para a exposição até o final deste parágrafo.

${ }^{9}$ A lista completa das funções de Genette inclui, entre os "temas do por que", a importância, a novidade, a unidade, a veracidade e a excusatio (quando o autor alega não ter o talento que o tema mereceria); entre os "temas do como" figuram a gênese, a escolha do público, o comentário do título, os contratos de ficcção, a ordem de leitura, as indicações de contexto, as declarações de intenção, as definições de gênero e as "esquivas" (quando o autor argumenta pela autosuficiência do texto e falta de necessidade de prefácios ou simplesmente fala de tema não relacionado ao livro).
} 
Genette observa que esta última função é típica das situações de inovação e transição históricas (Genette, 1999, p. 228), o que corresponde, em grande medida à situação estudada nesta exposição. Como observa del Lungo, apesar da "postura de poeticista", da intenção sistematizadora (reveladas no foco nas funções, na tipologia e nas definições sincrônicas), há no trabalho de Genette uma abertura para a análise do "elemento público da obra", uma "inflexão sobre a sociologia da literatura" (2009, p. 100-101). Haveria ainda uma abordagem histórica, muitas vezes implícita, porém limitada. A própria centralidade do livro como meio (Kreimeier; Stanizek, 2004; Reinhardt, 2018, p. 18) e das práticas de editoração fixadas a partir do século XVIII (von Ammon; Vögel, 2008, p. xiii) são índices dessa limitação. Tentando ampliar o âmbito da perspectiva histórica e, assim, o potencial analítico do estudo dos paratextos, Marot será enfático ao chamar a atenção para a importância da "inscrição dos textos liminares nos contextos culturais em que assumem seu sentido e suas funções" (2010, p. 8), ${ }^{10}$ aí incluídos, entre outros, "os contributos epistemológicos e genéricos que definem os territórios e os status dos escritos" (2010, p. 8), as condições de compreensão da leitura e a própria noção de obra.

A partir dessa concepção mais contextual e histórica do paratexto, o exame dos textos limiares aqui abordados nos apontará como as categorias da autoria e da obra serão particularmente mobilizadas. O sentido geral de instrução de leitura indicado por Genette, centrado na intenção e na recepção do texto, com isso ganhará contornos mais específicos. Com esta orientação teórica ampliada, vemos como o paratexto indica instâncias fundamentais para o processo de comunicação literária, conformando as noções de autoria e obra. É no paratexto que se constrói a coerência enunciativa que recria o sujeito na página (Marot, 2010, p. 12) a partir das relações e transações que, através do paratexto, assume tanto com a exterioridade do texto como com os seus próprios dados biográficos concretos (Gerstenbräun-Krug, 2018, p. 65), num fenômeno eminentemente moderno, produto das estéticas do gênio e da autonomia (Ott, 2010, p. 9). O paratexto é assim espaço para práticas de encenação da autoria, entendidas como ações e técnicas que visam atrair atenção visando assegurar um determinado posicionamento no campo literário, acumulando capital simbólico (Reinhard, 2018, p. 28). Noutras palavras, o paratexto será espaço de disputa por atenção e capital simbólico, de mediação entre o autor e seu público, como indica Genette, mas também entre o autor, o texto e o campo literário. Nele se constituirá uma instância que acolhe esforços por definir o lugar do autor e da obra no campo literário num momento específico. Na verdade, trata-se de um jogo comunicativo complexo, no qual o autor é uma referência importante, sendo, porém, uma peça entre outras no mecanismo da produção e circulação da literatura. Reinhard apresenta esse jogo como a criação de "marcos de percepção", de "marcos para a acolhida e disseminação ou transmissão da obra, ou sua rejeição e/ou esquecimento" (2018, p. 9-10, tradução nossa).

Cabe observar que o texto só poderá entrar nesse jogo como parte de uma obra, de um processo que se estabelecerá entre texto e paratexto. Como observa Marot (2010, p. 24), o paratexto pode transgredir a fronteira que o legava à margem do texto ao trabalhar na construção da unidade e da coerência do texto, convertendo-o em obra (ou, na terminologia de Marot, em "monumento", no sentido foucaultiano de signo de si mesmo). Os paratextos são, assim, integrados à obra, monumentalizando-se e, com isso, dialeticamente, conquistando sua autonomia relativa (enquanto agentes responsáveis pela monumentalização).

O paratexto também incidirá sobre a construção da percepção da unidade do texto (em última instância, da textualidade do texto), ao comunicá-lo publicamente como unidade

\footnotetext{
${ }^{10}$ Marot critica a historicidade de alguns pressupostos de Genette (daí propor "texto liminar" como alternativa a "prefácio", categoria mais histórica), fazendo-o, porém, para buscar um outro nível de sistematização, ao tentar descrever os "traços" de uma "escritura liminar" a partir de cinco "funções" apresentadas como "transistóricas" (2010, p. 13 et seq.), ainda que os mesmos argumentos que usa contra Genette possam ser direcionados contra as suas funções.
}

Rev. Bras. Lit. Comp. Niterói, v. 22, n. 40, pp. 84-103, mai. /ago. 2020

https://doi.org/10.1590/2596-304X20202240mmn 
(Reinhard, 2018, p. 9). Para além dessa propriedade mais fundamental, o paratexto poderá articular discursos portadores de dispositivos de inscrição de sentido no texto, não podendo ser dispensáveis, deslocáveis ou transitórios e relativizando a anterioridade (ou lateralidade) do texto (Marot, 2010, p. 22; del Lungo, 2009, p. 111). Como observa del Lungo, "o paratexto mobiliza um sentido, saberes e formas que o texto pode confirmar, desenvolver, mas também deslocar e mesmo infirmar" (2009, p. 104). Nesse sentido, é fundamental não perder de vista também a relevância do texto para o sentido dos prefácios, pois, como indica Lane, o paratexto "não adquire seu sentido senão na relação com o texto" (Lane, 1992, p. 147) e por isso, embora o nosso interesse se concentre no discurso paratextual, não se pode perder de vista a importância do texto para o sentido dos prefácios. No caso dos poemas narrativos aqui abordados, a presença de elementos da tradição épica nos textos será um importante elemento para a consideração de um discurso sobre a épica em contraste com o romance nos prefácios.

\section{Almeida Garrett}

Em 1828, Almeida Garrett, no exílio devido ao seu envolvimento com a causa liberal, publicou o poema Adosinda, romance publicado pelo Auctor da Historia da Lingua e Litteratura Portugueza na Collecção intitulada Parnaso Lusitano, do Poema Camões, Editor de D. Branca, \&a. \&a, \&a. Longe de ser a estreia literária de Garrett, o autor se identifica a partir da sua produção mais recente, na qual já se afasta da estética neoclássica que marcara a sua primeira produção. O texto é editado com dois prefácios, uma "Advertência", mais breve, e uma longa carta, endereçada a "D. L." (Duarte Lessa, um amigo do autor). Na advertência, identificando-se como "Autor deste romance", Garrett refere a acolhida positiva de "outras publicações suas" como principal motivação para a publicação da nova obra, "cujo assumpto é tirado da antiquissima tradição popular e se refere aos mais remotos tempos e costumes de nossas epochas heroicas e maravilhosas" (Garrett, 1828, p. iii). Está desde o início estabelecida a conexão entre interesse do público, tradição popular e passado nacional, conexão que será depois explorada em profundidade na carta. Trata-se de "um genero que fez a colossal reputação de Sir Walter Scott, e restituiu á antiga Escocia - na republica das lettras - o nome e independencia que ha tanto perdêra na ordem politica" (Garrett, 1828, p. iii). Ao justificar suas escolhas poéticas com o êxito de um autor estrangeiro indiretamente apresentado como modelo, Garrett evoca um sentido político com implicações relevantes. Ao buscar a matriz popular para a criação de seus poemas, Walter Scott (1771-1832) alcançara uma posição de destaque no campo literário a qual teria tido implicações para toda a comunidade nacional escocesa: a nova posição é apresentada como uma forma de compensação a uma situação extremamente desfavorável no campo político. O corolário dessas premissas é a projeção do próprio campo literário para uma posição de relevo, equiparável ou mesmo superior à política. Em Portugal, embora a situação política não estivesse favorável aos liberais, há uma missão cultural implicitamente comparável à de Scott: dar à cultura do país um lugar de maior destaque no concerto europeu das nações: "a lingua portugueza sahirá mais uma vez a próva singular de bisarria com as mais cultas e gabadas linguas da Europa" (Garrett, 1828, p. iv). Com o uso do romance, segundo o discurso prefacial, o autor define para si um lugar de prestígio no campo e, ao mesmo tempo, a imagem do campo literário.

Por sua vez, a carta endereçada ao seu amigo Duarte Lessa é um documento fundamental para compreender a maneira como Garrett entendia o potencial inovador do uso da poesia popular. ${ }^{11}$ Nela, Garrett apresenta Adosinda como uma primeira tentativa de "poema ou romance" de uma certa extensão, feito em redondilhas, metro que considera arcaico e natural, próprio para o canto, mas que teria caído em desuso com a introdução de metros italianos na

\footnotetext{
${ }^{11}$ Para uma apresentação do trabalho de Garrett com a poesia popular no contexto do do "folk revival" ver Marques (2009) e Boto (2011).
}

Rev. Bras. Lit. Comp. Niterói, v. 22, n. 40, pp. 84-103, mai. /ago. 2020

https://doi.org/10.1590/2596-304X20202240mmn 
Península a partir do Renascimento. Trata-se, para Garrett, do metro hispânico da herança de uma poesia "primitiva e eminentemente nacional" (Garrett, 1828, p. xi) criada pelos trovadores e expressa numa língua cujo nome se confunde com o do próprio gênero poético a que Garrett pretente filiar Adosinda: "romance". Segundo Garrett, sua iniciativa não estaria isolada no contexto europeu: depois de resgatada por Walter Scott, a contraparte escocesa dessa poesia se teria feito "da moda" (Garrett, 1828, p. xi) em toda a Europa por uma mudança de gosto, um esgotamento da estética neoclássica: "enfastiados dos olimpos" (Garrett, 1828, p. xii), poetas e público passaram a cultivar um interesse pela antiga poesia:

a poesia primitiva, a nossa propria, que não herdámos de Gregos nem Romanos, nem imitámos de ninguem, mas que nós modernos creámos, a abandonada poesia nacional das nações vivas, resuscitou bella e remoçada com suas antigas gallas, porêm melhor talhadas com suas feições primeiras. (Garrett, 1828, p. xiii).

"Primitiva" leva aqui o sentido de "originária", implicando uma substituição posterior por algo alheio, imitado. Chama a atenção o uso de "nacional" associado a "modernos", implicando não se tratar de um "nacional" particular, mas de uma condição compartilhada pelas diferentes nações modernas. "Poesia nacional" neste caso (e em muitos outros no universo textual que estudamos) não significa "poesia portuguesa", mas das nações europeias modernas, em oposição à poética clássica. O discurso da carta fala de um regresso, ou uma "restauração", porém em novos termos, uma espécie de salto de qualidade em função de um acúmulo ou aprendizado com a experiência de "espiritos e ouvidos costumados aos hymnos menos variados, porêm mais cadentes da antiguidade classica" (Garrett, 1828, p. xiv).

A "restauração" pode ser concebida como uma questão de ênfase, pois ao longo da história literária portuguesa, segundo Garrett, essa poesia originária a que chama de "gênero romântico", tivera alguma sobrevida, ainda que às margens do cânone. Na verdade, Garrett está indicando aqui o uso da redondilha na literatura portuguesa a partir do Renascimento, que praticamente desapareceria no século XVIII. A redondilha seria, segundo a carta, o metro natural do idioma, próprio do canto popular, presente nas mais antigas peças dos cancioneiros literários, mas também na poesia popular. Daí a importância, para a restauração da poesia que Garrett preconiza, da busca por esses textos ou fragmentos de textos que circulam na tradição popular e que poderiam tanto atuar como elos de ligação com as origens poéticas como servir, como veremos, de ponto de partida para novas criações.

A busca pelas fontes orais modernas, também abordada na carta, fará de Garrett o pioneiro desse tipo de investigação na Península. ${ }^{12}$ A história dessa busca elenca um feixe de temas e situações muito próprias do Romantismo: exílio, infância, solidão, cultura popular. Garrett conta na carta como

De pequeno [...] tinha um prazer extremo de ouvir uma creada nossa, em tôrno da qual nos reuniamos, nós os pequenos todos de casa, nas longas noites de hinverno, recitar-nos meio cantados, meio rezados, estes romances populares [...] de maravilhas e incantamentos, de lindas princezas, de galantes e esforçados cavaleiros (Garrett, 1828, p. xxii).

\footnotetext{
${ }^{12}$ Ao tratar, num trabalho de grande fôlego, da atividade de compilação de textos de fonte popular de Garrett, Boto afirma que "o confronto com os textos tradicionais terá aberto novos horizontes de trabalho a Garrett, que esquece a organização do cancioneiro" (2011, p. 19). A perspectiva de Boto, construída a partir de manuscritos anteriores à publicação de Adozinda, pressupõe um desvio de rumos no Garrett compilador. O prefácio de Adozinda sugere, antes, tratar-se de caminhos paralelos e complementares.
} 
Passada a infância, ainda que tomado de outros interesses, esses momentos seriam evocados nas horas de solidão. A leitura de Scott, que teria ocorrido no seu primeiro exílio em 1823, lhe sugere que "aquelas rudes e antiquissimas rapsodias nossas (...) podiam e deviam ser aproveitadas". Parte, portanto, para um trabalho de pesquisa bibliográfica que será pouco frutífero, o que o leva a consultar amigos para a recolha de textos orais. Com os primeiros textos recolhidos, descobre a importância das "amas secas e cozinheiras velhas, hoje principaes depositarias d'este genero de archeologia nacional" (Garrett, 1828, p. xxiv) e se dedica, já regressado do primeiro exílio, ao trabalho de recolha e transcrição de textos. Contudo, ainda no mesmo prefácio, Garrett não deixa de transparecer uma certa insatisfação quanto aos resultados obtidos e julga ser preciso trabalhar textualmente os materiais recolhidos, para que, "remoçados e ornados" pudessem ser publicados em um Romanceiro, o que só faria em 1843. Ficamos sabendo ainda através da carta, que, antes do seu segundo exílio em 1828, quando é preso, trabalhará no cárcere a matéria do poema recolhido sob o nome de "Silvaninha" para a feitura de Adosinda.

Há aqui, como em outros textos (inclusive o prefácio à segunda edição de Adosinda, de 1843), o pressuposto de que haveria um ponto em comum decisivo entre os textos que Garrett busca e a balada inglesa e alemã, assim como os romances de cavalaria que vinham sendo editados em antologias influentes na Inglaterra das primeiras décadas do século XIX. ${ }^{13}$ Embora o uso da redondilha se apresente como um traço decisivo para uma identidade poética ibérica, sobressai-se a ênfase sobre o fundo compartilhado: restauração inovadora da poesia narrativa de origem medieval. "Romance", "poema-romance", "poema romântico" e "poesia romântica" $" 14$ são termos que constam dos paratextos aqui estudados sem que neles o significado de cada um deles esteja claramente definido. De um modo geral, parecem indicar aquele fundo comum, de uma literatura narrativa de raízes medievais criada a partir de tradições orais mais fragmentárias e anônimas. Em alguns casos, o contexto se encarrega de esclarecer a especificidade dos termos. O "romance" que Garrett procura a partir da influência de Scott e outros antologistas e autores é o que hoje se convencionou chamar, no âmbito ibérico, de romance da tradição oral moderna (ou, no seu conjunto, romanceiro), a "balada ibérica": textos orais populares contemporâneos baseados em matrizes medievais, com as quais compartem uma série de características que atestam a continuidade de uma tradição. Algumas das matrizes

\footnotetext{
${ }^{13}$ Scott, por exemplo, acredita na origem dos romances em "cantos breves", ou seja, nas baladas (1834, p. 140). Referências a compiladores alemães e espanhóis só aparecerão no prefácio à segunda edição de Adosinda, no Romanceiro e cancioneiro geral, de 1843.

${ }^{14}$ O termo "poema romance" será usado também no discurso crítico. No artigo "Poesia: imitação - belo - unidade", publicado no Repositório Literário em 1835 (e depois compilado no volume IX dos Opúsculos), Alexandre Herculano usa o termo, atribuindo seu uso às obras de Dubois Fontanelle e Lemercier. Não localizamos o termo em Lemercier; já Dubois Fontanelle usa "épopée roman” (1813, p. 196) para descrever a épica renascentista italiana. Herculano emprega o termo com uma postura cética, negando-o indiretamente, para indicar as limitações da poética normativa, que teria criado categorias incapazes de dar conta de determinados textos: "Todos acham bellissimo o Orlando furioso, ainda ninguem o achou uno. A distincção de poema heroico, de poema romance, de Dubois, Fontenelle [sic], e de Mr. Lemercier nada mais é do que a impotencia absoluta de applicar a certas produccções as regras da antiga poetica" (Herculano, 1900, p. 53). Já em 1846 o jornal A Illustração: Jornal Universal, fundado por Garrett em 1845 e a partir de 1846 sob o comando de José Maria da Silva Leal, encontramos, como parte de uma série sobre a poesia épica, um artigo com o título de "Romance poema". Num caminho oposto ao ceticismo de Herculano, o termo aqui será adotado para nomear a poesia possível na modernidade: "os poetas comprehendem que para agradar é necessario que apresentem originalidade, paixões vivas, imaginação rica, quadros da natureza, e que as grandes dimensões da epopeia se encurtem e accomodem á pouca paciencia dos leitores, e eis aqui a origem do romance poema" (Anônimo, 1846, p. 91). O novo gênero será assim caracterizado: "este poema participa da epopeia cavalheiresca, e da tragedia, a sua época mais propria é a idade media, o seu maravilhoso a mythologia nacional, o seu theatro os castellos feudaes, os mosteiros, e o Oriente. Em vez de pintar os acontecimentos publicos, e as revoluções dos estados, pinta os crimes, as discordias, e as desventuras dos barões, e dos ricos homens, e o aspecto de cada paiz, e sobretudo os costumes dos tempos em que as acções se passam" (Anônimo, 1846, p. 91).
} 
medievais, que compõem o chamado "romanceiro velho", ganharam registros escritos a partir do século XV; já a partir do século XVI temos os chamados "romances novos", autorais e de cultura letrada. Di Stefano definirá assim o romanceiro:

O romanceiro é um gênero narrativo em verso com traços líricos mais ou menos marcados. Em sua formação influíram a poesia épica travadoresca e a poesia lírica, em um contexto de produção e consumo artísticos amplo, associado a tradições da literatura popular europeia. (di Stefano 2010, p. 7, tradução nossa).

O romanceiro ibérico diferencia-se da balada europeia, na qual encontra temas e motivos, sobretudo pela forma: uso da redondilha, rima assonante somente nos versos pares e única em todo o texto, ausência de estrutura estrófica ou número delimitado de versos. Outra característica apontada por Ana Valenciano é a correspondência rigorosa entre unidades sintáticas e métricas. Di Stefano destaca ainda o uso do ordo naturalis, assim como de uma retórica elíptica e alusiva, mas não eufemística. A narrativa se caracterizaria por um núcleo estrutural baseado no enfrentamento entre protagonistas ou destes com o próprio destino, com o narrador cedendo sistematicamente espaço para o discurso das personagens (traço marcadamente presente em Portugal segundo Ferré). Na verdade, trata-se de um elenco variado de histórias ou motivos associados a núcleos temáticos também variados (histórico, épico, religioso ou puramente ficcional) que vai sendo modificado pelos sucessivos "performers", respeitando-se porém as características formais e narrativas apontadas, o que resulta num grande número de variações, em geral disseminadas pelo espaço iberorromânico, para além da Península.

No entanto, transparece do prefácio de Adosinda uma nostalgia da origem, que faz Garrett considerar os textos que recolhe como "alguma coisa [que] se pôde obter informe, e mutilada pela rudeza das mãos e memorias por onde passou" (Garrett, 1828, p. xxv). Essas ruínas, contudo - e este é o centro da poética que o prefácio nos quer formular -, poderão ser, em grau variável, "remoçados" e "ornados com os enfeites singelos porêm mais symetricos da moderna poesia romantica". Adosinda será uma espécie de ampliação discursiva, com inúmeras alterações (cf. Pires, 2003; Marques, 2009), do romance intitulado "Silvaninha", a trágica história de uma adolescente que, por resistir ao assédio incestuoso do próprio pai, é mandada para a prisão, sem alimento e água, sobrevivendo por intervenção milagrosa, até o momento da sua libertação, quando morre. Embora considerando a redondilha como elemento chave do retorno à tradição, esse será o único elemento formal respeitado no poema de Garrett, e as características narrativas acima elencadas restarão muito transformadas. O que Garrett procura é fundamentalmente respeitar "o tom e stylo de melancholia e sensibilidade que faz o principal e peculiar character d'estas peças antiquissimas da nossa infancia poetica" (Garrett, 1828, p. xxvi). Garret está propondo a criação de textos baseados na relação hipertextual com poemas do romanceiro como caminho possível para uma renovação poética, uma ideia que ele próprio não voltaria a executar com a mesma ênfase, mas que será explorada por José Maria da Costa e Silva, autor que trataremos na sequência.

Outro elemento apresentado como potencialmente inovador no prefácio a Adosinda é o maravilhoso das crenças populares. Garrett vê no uso deste imaginário a possibilidade de abolir a mitologia clássica:

saciados das Venus e Apollos de nossos paes e avós, lembrámo-nos de ver com que maravilhoso enfeitavam suas ficções e seus quadros poeticos nossos bis e tres-avos: achámos fadas e genios, incantos e duentes - um stylo differente, outra face de coisas, outro modo de ver, de sentir, de pintar mais livre, mais excentrico, mais de phantasia, mais irregular porêm em muitas coisas mais natural (Garrett, 1828, p. xii). 
O maravilhoso desta ordem estará no centro de Dona Branca, ou A conquista do Algarve, poema publicado por Garrett em 1826, tendo o já então falecido poeta Filinto Elisio (1734-1819) como autor fíctício (na verdade, seu nome é apenas sugerido pelo uso das iniciais "F. E."). O prefácio (intitulado "Protestação") segue o jogo de máscaras autorais e, embora já refira o uso do maravilhoso popular nas suas primeiras linhas, não o associa a uma intenção poética renovadora; ao contrário, o discurso prefacial é escusatório e procura declarar ou esclarecer intenções: ainda que possa não parecer, o autor não quis ofender preceitos católicos. Isso porque Dona Branca, apesar de narrar a história de um amor frustrado e com fim trágico, é altamente erotizado e anticlerical. O poema conta a história dos amores da filha do rei Afonso III com o líder mouro Aben-Afan, último senhor de Silves, no Algarve, que a raptara. Levado por uma fada a ter de optar entre a glória guerreira e o amor, o herói escolhe o segundo e, depois de viver sua paixão, morre em combate, permitindo à jovem nação portuguesa conquistar o Algarve. $\mathrm{O}$ tema é histórico, porém os fatos foram adaptados por Garrett (o par amoroso sequer foi contemporâneo). Embora o poema apresente elementos narrativos que o aproximam da épica, um paratexto autoral, uma breve inscrição entre o prefácio e o texto, sem indicação de autoria, aponta para outra direção: "O assumpto deste romance e tirado da chronica de D. Afonso III de Duarte Nunes do Leão" ([Garrett], 1826, grifo nosso). A mesma filiação de gênero é reforçada em paratextos (prefácio e nota) da segunda edição, de 1848 (no prefácio à segunda edição, Garrett se refere ao poema como "meu inocentíssimo romance"). Que sentido terá "romance" aqui? Se pensamos no prefácio de Adosinda e, sobretudo, no que Garrett diz em outra carta ${ }^{15}$ a Duarte Lessa - carta que, desta feita, versa sobre Dona Branca em particular -, temos de pensar no romanceiro. Diz a carta:

Lembra-se das nossas conversas de Londres sobre antigualhas portuguezas e o muito que d'ellas se podia aproveitar quem de nossas legendas e velhas historias e tradições fizesse o que tam bem fazem inglezes e allemães, que é vestil-as dos adornos poéticos, e saccudirlhes a poeira dos séculos com bem assisada escolha e apropriado modo? Pois desde então (e já de mais tempo me fervia isto na cabeça) não fiz eu senão pensar no geito com que me haveria para armar assim uma cousa que se parecêsse, mas que de longe, com tanta cousa boa que por cá ha por estas terras de Christo, e que pelas nossas, de tam ricos que somos, se esperdiçam e andam a monte, por desacêrto de letrados e barbarismos de ignorantes. (Garrett, 1881, p. 350-351).

Contudo, diferentemente do que ocorre com Adosinda, não há referências disponíveis à tentativa de construção de uma relação hipertextual com o romanceiro. Fernando Ramos Machado (2017, documento eletrônico) aponta uma analogia estrutural entre as histórias de Dona Branca e a do romance "Miragaia", um dos primeiros recolhidos por Garrett, publicado na primeira edição do romanceiro de Garrett em 1843. Nas duas histórias, há nobres cristãs sequestradas por mouros pelos quais se apaixonam, e que ao final são mortos em lutas que implicam tomada de território. No entanto, a falta de uma referência explícita à relação entre os textos faz da hipótese de relação hipertextual mera conjectura. Além disso, matéria narrativa semelhante à apontada acima encontra-se também no Oberon, de Wieland, obra cuja relação com Dona Branca Garrett indica em mais de uma instância. ${ }^{16} \mathrm{~A}$ intenção de que a obra

\footnotetext{
${ }^{15}$ Seguindo Genette, a carta poderia ser também considerada paratexto. Neste caso, um epitexto, um paratexto que não compartilha o espaço físico do livro. O epitexto é um conceito mais complexo do que a formulação de Genette apresenta (Ott, 2010; Reinhard, 2018; Gerstenbräun-Krug, 2018). Por limitações de espaço, não incluímos esta categoria neste trabalho.

${ }^{16}$ Não por acaso o autor anônimo do artigo sobre o "Romance poema" considere também o Oberon como "o primeiro poema que conhecemos deste genero, em tempo, e talvez em merecimento" (Anônimo, 1846, p. 91). Para
} 
pretendida "se parecêsse, mas que de longe" com o material disponível também aponta para o fato de que a ideia de apropriação e criação hipertextual a partir de um romance não estivesse na gênese de Dona Branca, poema que, ressalte-se, antecede Adosinda na publicação e, ao que tudo indica, na gênese.

Desse modo, a intenção de filiação de gênero do breve paratexto de Dona Branca limitase a apelar para aquele fundo comum de poesia narrativa de origem medieval antes referido. Ou seja, "romance" será usado aqui para além do seu sentido ibérico, e o prefácio procura preparar a recepção do poema como continuador do romance (romanesco). Mais do que estabelecer uma relação hipertextual com um poema do romanceiro em particular, Dona Branca vai filiar-se arquitextualmente ao romance (romanesco).

O breve paratexto que apresenta o poema como romance, também é preciso salientar, apresenta a crônica histórica como fonte da matéria poética. Esta referência nos permite sondar referências indiretas à épica. É verdadeiro que o Oberon constitui o intertexto mais evidente, sendo fundamental para o poema de Garrett; contudo, ainda que as referências a Scott nos paratextos da primeira edição de Dona Branca se limitem a uma única instância (uma nota ao segundo canto), sabemos pelos paratextos de Adosinda, mas também por uma carta do autor sobre o seu poema Camões, de como as experiências de Scott com a poesia popular e o romance foram decisivas para a moldagem da poética dos poemas de Garrett neste momento. Isso nos autoriza a buscar em Scott um discurso sobre a épica para tentar entender o discurso sobre a filiação de gênero contido nos paratextos de Dona Branca. No prefácio a um poema decisivo para a projeção de Scott no campo literário inglês (e depois europeu), The bridal of Triermain, de 1813, encontramos uma tese já antes apresentada por Thomas Percy (1729-1811), o grande difusor do interesse pela balada e o romance na Inglaterra ainda do século XVIII, no seu "Essay on the ancient metrical romances" (Percy, 1877). Segundo ambos os autores, nas suas matrizes, a poesia épica representaria um ponto de equilíbrio entre conhecimento histórico acumulado e criação poética imaginativa. A partir de um determinado momento, a preocupação com a conservação do conhecimento histórico ganharia preponderância, abrindo espaço para outro gênero poético, caracterizado pela ficcionalidade e pela invenção, em que a arte triunfaria sobre a autenticidade e a imaginação sobre a verdade: o romance. Em contraste com a poesia épica, portanto, o valor conferido à referência à realidade histórica perderia em importância em comparação com a liberdade da imaginação. Ao mesmo tempo, a representação de temas e personagens de interesse público cederiam lugar à representação de questões de alcance mais individual.

A partir dessa oposição entre épica e romance, entre verdade e imaginação, fato e ficção, divisamos uma ambiguidade implícita à filiação de gênero na breve inscrição paratextual de Dona Branca. Entre romance e narrativa baseada numa crônica histórica, constroem-se expectativas divergentes que duplicam e confirmam a ambiguidade já apresentada no título do poema: Dona Branca, ou A conquista do Algarve. Ao nomear o poema com uma figura histórica feminina, o título suprime expectativas possíveis de filiação do texto à tradição épica, onde raramente a heroicidade feminina é alçada a centro temático e, desse modo, ao título de um poema. Por outro lado, a referência a um episódio da história militar portuguesa indica contextos bélicos e encenação de heroicidade(s) masculina(s). ${ }^{17}$

Essa mesma ambiguidade, pautada na oscilação entre o épico e o romanesco, o histórico e o fictício, encontramos no poema Camões como objeto do discurso prefacial: "nem será difícil

o autor, "seria mui difficultoso achar poema, em que todas as cores do estylo, desde o sublime até ao burlesco, desde o pathetico mais violento até á moral mais severa, se encontrem tão destramente enlaçadas, é um orgão, em cujos sons se confundem ás vozes de todos os instrumentos!" (Anônimo, 1846, p. 91).

${ }^{17}$ Por não levar em conta as possibilidades e o alcance das transformações da épica no século XIX (Friedlein, 2019), Marques nega a possibilidade de considerar a dimensão épica de Dona Branca, senão como "caricatura da epopeia" (2009, p. 199). 
ao leitor o distinguir, no meu opúsculo, o histórico do imaginado: mas não separará de certo muita cousa, porque das mesmas ficções, que introduzi, tem sua base verdadeira as mais dellas" ([Garrett], 1825, p. vi). ${ }^{18}$ Essa ambiguidade encontra uma contraparte na rejeição da polarização estética: "Nao sou clássico, nem romântico: de mim digo que não tenho seita, nem partido em poesia (assim como em cousa nenhuma); e por isso me deixo ir por onde me levão minhas ideias boas ou más, e nem procuro converter as dos outros, nem inverter as minhas nas delles: isso é para literatos de outra polpa, amigos de disputas, e questões, que eu aborreço." ([Garrett], 1825, p. vi). A ambiguidade e a rejeição reivindicam para o autor e seu poema um lugar sui generis no campo literário, situação que voltaremos a encontrar nos textos analisados e que trataremos em conjunto na parte final deste trabalho.

\section{Costa e Silva}

As poucas e quase sempre brevíssimas referências da crítica e da historiografia aos poemas longos que José Maria da Costa e Silva publicou nos anos $1830^{19}$ geralmente indicam como eles tomam o caminho aberto por Garrett na Adosinda. Com razão, observou-se como Isabel, ou a heroína de Aragão (1832) e O espectro, ou a baronesa de Gaia (1838) partem da coleta e do estabelecimento de versões de romances para, a partir deles, apresentarem um trabalho de elaboração poética individual. Costa e Silva, também levado por uma motivação renovadora da poesia, manifesta uma tendência que valoriza mais a criação individual, dando, ao mesmo tempo, mais espaço a elementos buscados na épica. Muito mais do que Garrett, sucinto quanto à épica nos paratextos que examinamos, Costa e Silva refletirá sobre a situação do gênero no contexto das inovações introduzidas com o Romantismo.

No prefácio a Isabel, Silva conta como, depois de ter lido a Adosinda por sugestão de um amigo, foi por ele instado a produzir algo semelhante, para o que teriam partido para a "pesquisa dos necessarios Romances" (Silva, 1832, p. iv). Não ficamos sabendo mais nada a respeito dessa pesquisa conjunta. Somente no prefácio a $O$ espectro é que somos informados de uma fonte: uma senhora que havia aprendido romances da mãe, em Goa. Contudo, não sabemos se terá sido ela a fonte do romance que serve de base para Isabel, que Costa e Silva conhece, ao que parece, pelo título de "Heroína de Aragão", e que Garrett vai depois publicar sob o título de "Donzela que vai à guerra".

O romance é bem conhecido. Na versão de Costa e Silva, Isabel quer defender o nome do velho pai lutando na guerra disfarçada de homem; diante da recusa do pai, que alega que a filha será reconhecida, a princesa desobedece e parte. No desenrolar da guerra, um outro guerreiro se sente atraído pelo "companheiro" de armas e, estando convencido de que se trata de uma mulher, põe-na a prova quanto a sua identidade. Assim como em Dona Branca, também aqui tudo dependerá do papel exercido por uma fada, que promete êxito a Isabel, desde que seja capaz de resistir à atração que também sente pelo seu colega combatente. A heroicidade de Isabel, incontestável, insere o poema arquitextualmente no âmbito da poesia épica, ${ }^{20}$ articulando-se em vários níveis: sua excelência se mostra tanto no combate como na astúcia e

\footnotetext{
18 Essa mesma situação se observa em alguns dos epitextos do poema: no Parnaso lusitano, Garrett elenca o poema Camões entre os épicos; contudo, ao mesmo tempo, em carta de 1824 afirma: "Dei-lhe um tom e ar de romance para interessar os menos curiosos de letras, e geralmente fallando o estylo vae moldado ao de Byron e Scott (ainda nâo usado nem conhecido em Portugal) mas não servilmente e com macacaria, porque sobretudo quiz fazer uma obra nacional." (Garrett, 1881b, p. 346). Segundo Curran (1986, p. 137), Scott conceberia o romance como o "encantamento do presente pelo passado", o que aproximaria a leitura do Camões pela chave do romance (aqui tão somente esboçada) às leituras pela saudade e pelo regresso sebastianista da "essência" da Pátria pela cultura (Lourenço, 1999, p. 19, 32 e 143 et seq.).

${ }^{19}$ Uma exceção de monta será Marques (2012).

${ }^{20}$ Compreendemos a heroicidade como um dos critérios definidores da poesia épica.
} 
na prudência, resistindo ao impulso amoroso. Sua ação excepcional a converte em heroína fundadora, de quem "Alta Prole vira, que, a Patria honrando / Hum dia de Aragom occupe o Solio" (Silva, 1832, p. 113).

O tratamento tipográfico dado ao romance original recolhido é sintomático da diferença de atitude entre Garrett e Costa e Silva. Em Adosinda, ficamos conhecendo a versão colhida por Garrett como nota do autor, ao final do texto. Essa situação paratextual parece indicar que o conhecimento do texto original não é relevante para a leitura do poema. Isso faz supor uma unidade profunda entre as duas "versões" do romance, uma sendo, nas palavras do autor, "imitação" da outra. Por seu turno, Costa e Silva apresenta o "romance original" - observe-se que Garrett fala em "original deste" romance (o grifo é nosso) - com as mesmas características tipográficas do seu poema, em posição destacada, logo após o "Prólogo", o que propõe uma leitura prévia ao texto de Costa e Silva. Com isso, os dois textos ganham um mesmo estatuto no contexto do livro. Esse paralelismo, no entanto, é parte de uma retórica:

Ahi a dou agora [Isabel] á luz com o Romance original, pera que os Leitores possão melhor ajuizar do trabalho, que tive com esta Producçõm, e dos ornatos, que lhe juntou esse pouco cabedal poético, com que me dotou a Natureza (Silva, 1832, p. iv).

Dar a conhecer a versão colhida do romance tem o propósito de possibilitar a avaliação crítica do trabalho poético de Costa e Silva, sendo essa avaliação parte do sentido do texto. Se o movimento de Garrett é na direção do retorno sentimental, em sentido schilleriano, ao uso de um repertório próprio de um Volksgeist, Costa e Silva se aproxima das poéticas do gênio criador.

he tempo de que o colorido poetico vá animando, e fazendo valer os agradaveis sonhos, que nos embellezaram na infancia, e de que a mão do Genio pode tirar effeitos tão sublimes como das Fabulas antigas, com a vantagem não pequena de dar á Poesia hum colorido mais nacional. (Silva, 1836, p. 7).

O nacional é concebido como cor local, não associado a uma essência nacional particular (daí, por exemplo, termos o uso de uma balada escocesa de Scott recontextualizada em Emília e Leonido, de 1836). O nacional perde em grande medida o seu sentido ideológico-identitário e limita-se a sua potencialidade para um projeto estético. É através do uso da cor local (ou das cores locais) que os poetas poderão libertar-se do "miseravel jugo da imitaçom [...] fazendolhes produzir em vez de Composições originaes, Paraphrases ou Traducções livres dos Poemas da Antiguidade" (Silva, 1832, p. v).

A retórica de Costa e Silva gira em torno de uma semântica da ruptura, portanto, não tanto da do regresso. Em outros dois aspectos, as divergências com as ideias de Garrett serão mais evidentes: na métrica e no uso do maravilhoso. A redondilha deixa de ser um critério definidor do romance para Costa e Silva, que usará o decassílabo nos seus poemas narrativos dos anos 1830 , porque, segundo o autor "versos de medida pequena non se accomodavam bem com as longas descripsões, que o meo assumpto requeria" (Silva, 1832, p. ix). A liberdade de criação sobrepõe-se ao critério rítmico que, cabe lembrar, para Garrett associa-se ao componente musical da tradição oral e mesmo literária, sendo-lhe intrínseco.

Quanto ao maravilhoso, embora a sua concepção de um maravilhoso moderno construído a partir do uso do imaginário popular coincida com a de Garrett, vamos perceber que, no prefácio a Isabel, ela ganha uma ênfase muito maior. A discussão associa a pertinência ou não do maravilhoso mitológico clássico a um quadro dos gêneros literários: admissível na poesia filosófica, na lírica e na pastoril, na épica, porém, enquadrando a ação de heróis cristãos, ela "parece desacerto, inverosimilhança, e falta de ciso" (Silva, 1832, p. vi). O novo maravilhoso é próprio do romance, mas fará sentido também para a épica, que poderá representar com mais 
particularidade a coletividade nacional: "Torna-se ainda mais verosimil a sua admiçom no tecido Epico, por que, sendo os Magos de diferentes Nações, he natural, que trabalhe cada hum delles pola prosperidade da sua Patria, e dos seos Conterraneos" (Silva, 1832, p. vii). Embora o problema do maravilhoso, central para as discussões sobre o fim da épica no século XIX, pareça assim resolvido, o subtítulo dos poemas e as indicações paratextuais deixam evidente a intenção de relação genérica com o romance. No entanto, a épica se manterá no horizonte da renovação poética para Costa e Silva, tanto no plano formal como no temático. No prefácio a O espectro, ou A baronesa de Gaia, de 1838, uma amplificação em oitavas-rimas do romance "Bernal Francês", também colhido de fonte oral por Garrett, afirma o autor: "Escrevendo em verso rimado, procurei quanto pude imitar o estilo dos nossos antigos epicos, o seu tom, e as suas maneiras" (Silva, 1838, p. 10). Essa indicação da opção formal do poeta divide espaço no prefácio com a explicitação da relação hipertextual com o "Bernal Francês", que é seguida de algumas reflexões sobre o romanceiro. No entanto, o que parecia a confissão de uma adoção intencional de tendências estilísticas da tradição épica, revelador de um projeto poético, será logo neutralizado pela revelação da verdadeira gênese da opção pela rima:

resolvi escrever este poema em outavas, que he a combinaçâo rythmica, que elles [os leitores que criticaram o uso de versos brancos em Isabel] julgam mais sublime, talves sem mais razâo que estarem costumados a ouvir gemer em outavas a bella Castro, suspirar Hermina, e trovejar Adamastor. (Silva, 1838, p. 6).

\section{Antonio Augusto Corrêa de Lacerda}

Tem-se notícia de duas obras publicadas por Antonio Augusto Corrêa de Lacerda (? 1868), fidalgo alentejano formado em matemática em Coimbra, militar e membro do Conservatório Real de Lisboa: A Rainha e a Aventureira: Drama em prosa, premiado pelo Conservatorio Real de Lisboa, e representado no Theatro da rua dos Condes (1844) e Dom Sebastião, o encoberto, romance-poema (1839). Dom Sebastião é uma fantasia histórica sobre a morte do rei: Lacerda narra como o Rei D. Sebastião, após sua derrota na África, é acolhido como guerreiro desconhecido pela família de um jovem árabe que fora salvo por ele em combate. Um amigo da família, filho de um português feiticeiro exilado, é pretendente da irmã do jovem salvo pelo rei, uma cantora que se apaixona por Sebastião. O pretendente, que quer usar o poderoso prisioneiro para ascensão política, força a família a entregá-lo, mas essa resiste e pega em armas para defender o hóspede, que acaba por morrer em combate ao final do poema. A narrativa encerra com o discurso arrependido do espectro do rei e a criação da sua volta no imaginário popular.

No prefácio, exprimindo uma consciência de que talvez tenha exagerado no número de mortes no interior da narrativa, o autor observa que isso o "fará porventura parecer cruel, ou (como dizem outros) romantico." A ironia, de sabor byroniano, prossegue:

Tão indeterminadas, e confusas são as raias do chamado - romantico; tanto abuzo se tem feito d'esta palavra, e do que ella exprime, que é bem facil a qualquer adaptal-a ao sujeito, que tracta; mas por isso mesmo bem difficil empregal-a com propriedade" (Lacerda, 1839, p. iii).

O discurso prefacial segue procurando dar coordenadas para a recepção do poema, primeiro situando-o quanto à orientação poético-estilística: 
Não é este um poema classico; a falta de alguma das unidades, as digressões extensas, e um certo vago contemplativo, e apaixonado, o excluem da communhão classica. - Para romantico é muito historico, e appresenta muitas feições classicas; táes são as descripções dos combates, \&c (Lacerda, 1839, p. iii).

Observe-se como, seguindo a mesma concepção teórica de Percy e Scott, o "romântico" se define por oposição ao histórico: "poema romântico" aqui parece equivaler ao romance dos autores anglo-saxões. Transpondo-se para o prefácio de Lacerda o binarismo dos autores ingleses, "poema clássico" deveria corresponder a "poema épico". Lacerda, contudo, não usa o termo, apesar da referência à encenação de combates como própria do "poema classico". Seu poema, portanto, infere o prefácio, estaria, assim como Dona Branca e Camões, numa posição ambígua entre o clássico e o romântico.

Na sequência, Lacerda procura justificar a indicação de gênero que incluíra, no título do texto, "romance-poema": "Não lhe chamei simplesmente Poema; porque este titulo persi só dá a entender, que é um poema classico." (IV) Ou seja, "poema clássico" (que poderia corresponder a "poema épico") seria uma redundância. Segue o prefácio: "Não the chamei Poema-Romantico, porque tal não o reputo rigorosamente" (IV), para concluir: "Finalmente dei-lhe o [nome] de Romance-Poema na falta de outro melhor". Na fórmula que encontra para dar conta da hibridez do seu poema, "romance" afinal substitui, por equivalência, "poema romântico", tanto como "poema" equivale ao "poema épico". A referência indireta ao poema épico não o exclui do horizonte, já construído com a referência ao protagonista no título.

\section{Macedo}

No Brasil, Joaquim Manoel de Macedo publicou em 1855, no tomo III, n. 2 de $O$ Guanabara, o "Fragmento de um poema-romance - Nebulosa. Canto III" (1855, p. 51-56). O poema completo seria lançado em livro em 1857 sob o título de A nebulosa, sem a indicação de gênero contida no fragmento publicado no Guanabara. Contudo, talvez por constar como "poema-romance" em anúncios e catálogos impressos e no Dicionário bibliográfico de Inocêncio Francisco da Silva (1860), o subtítulo tem acompanhado o poema de Macedo pela historiografia. Apesar da evidente relação arquitextual com o romance medieval - atestada nas sucessivas frustrações amorosas, no maravilhoso e nas bruxas, e nas peripécias -, a crítica tem insistido em considerar a indicação paratextual como referência ao romance moderno (o novel dos ingleses), o que de fato ocorrerá em textos da segunda metade do século XIX.

\section{Considerações finais}

Os paratextos aqui analisados apresentam o poema narrativo como foco das preocupações com a renovação literária nas décadas iniciais do Romantismo em Portugal e, em menor medida, no Brasil. ${ }^{21}$ Como paradigma do poema narrativo nos cânones clássicos, a épica não deixará de se fazer presente no rol dessas preocupações. Contudo, a ênfase parece residir na inovação e no romance (como romanesco e/ou como romanceiro) como vetor das transformações literárias, não havendo nos discursos, como se poderia esperar, referências ao prestígio do poema épico nos cânones literários. Os paratextos parecem, antes, não querer pôr o gênero no horizonte do leitor, ainda que não transpareça, é verdade, a intenção de suprimi-lo. Há um conjunto variado de estratégias para mantê-lo no horizonte, sem que ele receba uma posição privilegiada ou seja

\footnotetext{
${ }^{21}$ Backès (2003) argumenta que esta tendência se observaria na Europa, em geral, sobretudo a partir do impacto renovador dos poemas de Ossian/Macpherson, cujos poemas marcados pela presença do poeta e pelas construções elípticas, alusivas e analépticas, romperiam com o que o chamou de "modelo virgiliano" (presença de narrador discreto e encadeamento de episódios, número limitado de reversões da ordem cronológica e dimensão nacional). 
o foco das atenções, o que parece ocorrer mesmo naqueles casos em que é evidente a presença de elementos formais e temáticos da poesia épica nos poemas (como em Isabel, Dom Sebastião, o encoberto, Camões e, em menor grau, Dona Branca).

De um modo geral, os prefácios apresentam uma reflexão sobre os textos a partir das instruções de filiação de gênero (entenda-se filiação ao romance), indicando o trabalho hipertextual com a balada e/ou arquitextual com o romance. E apesar de não haver uma discussão sobre o gênero como sistema de referência, um gênero literário em particular é apresentado como fonte de renovação ou restituição de uma tradição muito próxima de um núcleo identitário.

Os paratextos apresentam a figura do autor como sujeito do processo de transformação ou atualização do campo literário. No caso de Adosinda, isso significa acompanhar os novos tempos, porém através de uma conciliação entre a tradição local que sobrevive nas fontes populares como ruínas de uma origem perdida e a literatura importada pelo neoclassicismo, responsável, apesar de tudo, na visão expressa na carta a Duarte Lessa, por uma educação do gosto poético. Já Costa e Silva e Lacerda se apresentam mais independentes quanto à tradição popular. Costa e Silva, em particular, embora reconhecendo o potencial da poesia popular, a poética do gênio se apresenta como um componente inovador capaz atuar livremente mesmo sobre o legado popular. Este aspecto é reforçado pelo recurso à encenação do histórico pessoal e da vida privada, traço compartilhado com Garrett, inclusive pela publicação de um documento privado como paratexto. Este recurso está em sintonia com a estética individualizante do romance, tal como teorizado (e praticado) por Scott.

No caso de Adosinda e dos poemas de Costa e Silva, os prefácios chamam a atenção para a construção da relação hipotextual que fundamenta os poemas. Contudo, será um papel decisivo desempenhado pelo paratexto: explicitar a alteridade com relação à "fonte" e estabelecer o limite entre os textos, definindo a obra. Em Costa e Silva, os paratextos chegam a propor (quase a impor) explicitamente uma confrontação textual. Nesse sentido, muito mais do que instruir a leitura, os prefácios ofertam uma constelação de sentidos que influi decisivamente sobre a leitura do texto, perdendo a sua condição de suplementaridade.

Por fim, destacamos a interface com a poesia épica nos paratextos que articulam um discurso que aponta para uma filiação de gênero ambígua, oscilando entre o épico e o romanesco, o histórico e o imaginado (os de Dona Branca e Camões, Dom Sebastião, o encoberto e, em menor grau, $O$ espectro). A oscilação constrói uma retórica da obra inclassificável, que transcende as limitações dos discursos teóricos. Como obra sui generis, entre o histórico e o imaginado (ou para além do par clássico x romântico), os poemas são apresentados para um leitor e um campo despreparado para esse tipo de obra. Constrói-se um discurso da singularidade e da inovação conforme às poéticas do gênio que, como vimos no caso da "Advertência" de Adosinda, poderá mobilizar o próprio sentido do campo literário como um todo. Em suma, as referências - ainda que elípticas ou indiretas - à poesia épica comporão um importante fenômeno associado aos paratextos como espaço de negociação da posição de obras e autores no campo literário português da passagem para o Romantismo.

\section{REFERÊNCIAS}

ANÔNIMO. Romance poema. A Ilustração: Jornal Universal, v.2, n.6, p. 91-93, set. 1846, http://docvirt.com/docreader.net/RealGabObrasRaras/28510

BACKÈS, Jean-Louis. Le Poème narratif dans l'Europe romantique. Paris: Presses Universitaires de France, 2003. 
BENSIMON, Nella Bianchi, and DARBORD, Bernard, and Marie-Christine GOMEZGÉRAUD, orgs. Le choix du vulgaire - Espagne, France, Italie (XIIIe-XVIe siècle). Paris: Garnier, 2015.

BOTO, Sandra Cristina de Jesus. As fontes do Romanceiro de Garrett e proposta de uma edição crítica. Tese (Doutorado em Estudos Literários) - Universidade Nova de Lisboa, Lisboa, 2011.

CURRAN, Stuart. Poetic form and British Romanticism. Oxford: Oxford University Press, 1986.

DECLERCQ, Gilles, and MURAT, Michel. Le romanesque. Paris: Presses de la Sorbonne Nouvelle, 2004.

DEL LUNGO, Andrea. Seuils, vingt ans après: quelques pistes pour l'étude du paratexte après Genette. Littérature, v.155, n.3, 2009, p. 98-111.

DI STEFANO, Giuseppe. Romancero. Madrid: Castalia, 2010.

FONTANELLE, J. G. Dubois. Cours de belles-lettres. Paris: Gabriel Dufour, 1813, v. 2.

DUFF, David. Romance. In: MAC CALMANN, Iain, org. An Oxford Companion to the Romantic Age: British Culture 1776-1832. Oxford: Oxford University Press, 1999, p. 682.

DUFF, David. Romanticism and the uses of genre. Oxford: Oxford University Press, 2009.

DUNCAN, Ian. Modern romance and transformations of the novel: the gothic, Scott, Dickens. Cambridge: Cambridge University Press, 1992.

FERRÉ, Pere. Romanceiro português da tradição oral moderna: versões publicadas entre 1828 e 1960. Lisboa: Fundação Calouste Gulbenkian, 2000.

FRIEDLEIN, Roger. A validade do discurso autorreflexivo em Almeida Garrett: D. Branca (1826 e 1848). In: FRIEDLEIN, Roger; NUNES, Marcos Machado; ZILBERMAN, Regina. A epopeia em questão: debates sobre a poesia épica no século XIX. Rio de Janeiro: Edições Makunaima, 2019.

http://www.edicoesmakunaima.com.br/catalogo/2-critica-literaria/37-a-epopeia-em-questao

FRYE, Northrop. Anatomy of criticism: four essays. Princeton: Princeton University Press, 1957.

[GARRETT, João Baptista Leitão de Almeida]. Camões, poema. Paris: Na Livraria Nacional, 1825.

[GARRETT, João Baptista Leitão de Almeida]. D. Branca ou A conquista do Algarve: obra posthuma de F. E. Paris: Aillaud, 1826.

GARRETT, [João Baptista Leitão de] Almeida. Adozinda, romance. Londres: Boosey and Son, 1828. 
GARRETT, [João Baptista Leitão de] Almeida. Dona Branca. Porto: Livraria Chardron de Melo e Irmão, 1848.

GARRETT, [João Baptista Leitão de] Almeida. Ao Sr. D. L. [Duarte Lessa]. In: AMORIM, Francisco Gomes de. Garrett: memorias biographicas. Lisboa: Imprensa Nacional, 1881a, p. 350-362. [1824]

GARRETT, [João Baptista Leitão de] Almeida. Julho 27 (1824). In: AMORIM, Francisco Gomes de. Garrett: memorias biographicas. Lisboa: Imprensa Nacional, 1881a, 345-347. [1824]

GENETTE, Gérard. Seuils. Paris: Seuil, 1999. [1987]

GERSTENBRÄUN-KRUG, Martin. Paradigma Paratextualität. Einsichten und Aussichten. Zum Potential eines paratextuellen Forschungsansatzes für die Beschreibung moderner Autorschaft. In: GERSTENBRÄUN-KRUG, Martin, and REINHARD, Nadja, orgs. Paratextuelle Politik und Praxis: Interdependenzen von Werk und Autorschaft. Viena, Böhlau, 2018. p. 53-70.

HERCULANO, Alexandre. Poesia: Imitação - Belo - Unidade. In: HERCULANO, Alexandre. Opúsculos. Lisboa: Bertrand, 1900. V. 9, p. 21-72 [1835]

KREIMEIER, Klaus, and STANIZEK, Georg, orgs. Paratexte in Literatur, Film, Fernsehen. Berlim: Akademie Verlag, 2004.

LACERDA, Antonio Augusto Corrêa de. Dom Sebastião, o encuberto: romance-poema (notas abreviadas). Lisboa: Typographia de J. F. Sampaio, 1839.

LANE, Philippe. La péripherie du texte. Paris: Nathan, 1992.

LOURENÇO, Eduardo. Portugal como destino, seguido de Mitologia da saudade. Lisboa, Gradiva, 1999.

MACEDO, Joaquim Manoel de. A nebulosa. Rio de Janeiro: J. Villeneuve, 1857.

MACEDO, Joaquim Manoel de. Fragmento de um poema-romance - Nebulosa, Canto III. $O$ Guanabara, t. III, n. 2, 1855, p.51-56.

MACHADO, Fernando Ramos. A Dona Branca, de Garrett. 2017. http://domedioorienteeafins.blogspot.com/2017/01/a-dona-branca-de-garrett.html

MAGALHÃES, Gabriel Augusto Coelho. Garrett e Rivas: o Romantismo em Espanha e Portugal. Lisboa: Imprensa Nacional - Casa da Moeda, 2009.

MAROT, Patrick. Pour une poétique historique des textes liminaires. In: MAROT, Patrick, org. Les textes liminaires. Toulouse: Presses Universitaires du Midi, 2010. p. 7-27.

MARQUES, J. J. Dias. The oral ballad as a model for written poetry in the Portuguese Romantic Movement: the case of Garrett's Adozinda. In: GOLOVAKHA, Inna, and VAKHNINA, Larysa, orgs. 35th International Ballad Conference SIEF: papers and materials. Kiev: National 
Academy of Sciences of Ukraine; Rylsky Intitute for Art Studies, Folklore and Ethnology, 2009. p. 145-159.

MARQUES, J. J. Dias. The oral ballad and the printed poem in the portuguese Romantic movement: the case of J. M. da Costa e Silva's Isabel, ou A heroina de Aragom. In: CAMPBELL, Matthew, and PERRAUDIN, Michael. The voice of the people: writing the European folk revival, 1760-1914, orgs. Londres: Anthem Press, 2012. p. 87-102.

McLANE, Maureen N. Balladeering: minstrelsy, and the making of Romantic poetry. Cambridge: Cambridge University Press, 2008.

OTT, Michael Ralf. Die Erfindung des Paratextes. Überlegungen zur frühneuzeitlichen Textualität. Frankfurt: Elektronische Universitätspublikation der Goethe-Universität Frankfurt, 2010, http://publikationen.ub.uni-frankfurt.de/files/7858/Erfindung_des_Paratextes.pdf

PERCY, Thomas. Essay on The Ancient Metrical Romances. In: PERCY, Thomas. Reliques of ancient English poetry, consisting of the heroic ballad songs and other pieces of our earlier poets, together with some few of later date. Londres: Cassell, Petter and Galpin, 1877. V. 3, p. ix-Xxxv [1767].

PIRES, Maria da Natividade. Romance da Silvana e Adozinda: da memória coletiva à criação individual. In: MONTEIRO, Ofélia Paiva, and ALMEIDA, Maria Helena Santana. Garrett, um romântico, um moderno. Actas do congresso internacional comemorativo do bicentenário do nascimento do escritor. Lisboa: Imprensa Nacional - Casa da Moeda, 2003. p. 329-338.

REINHARDT, Nadja. Paratextuelle Politik und Praxis - Einleitung. In: GERSTENBRÄUNKRUG, Martin, and REINHARD, Nadja orgs. Paratextuelle Politik und Praxis: Interdependenzen von Werk und Autorschaft. Viena, Böhlau, 2018. p. 9-26.

SCHAEFFER, Jean Marie. Le romanesque. Vox Poetica, 2002, http://www.voxpoetica.org/t/leromanesque.htm.

SCHÖNEICH, Christoph. Romance. In: BURDORF, Dieter; FASBENDER, Christoph and MOENNIGHOFF, Burkhard, orgs. Metzler Lexikon Literatur: Begrife und Definitionen, 3., völlig neu bearbeitete Auflage. Stuttgart/Weimar, Metzler, 2007. p. 662.

SCOTT, Walter. Essay on romance. In: Essays on chilvalry, romance and the drama. Robert Cadell - Whittaker and Co, 1834. p. 127-215. [1824]

SCOTT, Walter. Preface. In: SCOTT, Walter. The Bridal of Triermain, or The vale of St. John. Edimburgo: James Ballantyne, 1813. p. vii-xvii.

SILVA, José Maria da Costa e. Emilia, e Leonido, ou os amantes suevos: poema. Typografia de A.S. Coelho e Cia, 1836.

SILVA, José Maria da Costa e. Isabel, ou a heroina de Aragom. Lisboa: Impressão Régia, 1832.

SILVA, José Maria da Costa e. O espectro, ou a baronesa de Gaia. Paris: Guiraudet e Jouast, 1838. 
STIERLE, Karlheinz. Zwischen Romanus und Romantik: Wandlungen eines europäischen Schlüsselbegriffs. In: ERNST, Anja; GEYER, Paul (eds.). Die Romantik: ein Gründungsmythos der Europäischen Moderne. Bonn: V\&R unipress; Bonn University Press, 2010. p. 55-82.

VON AMMON, Frieder, and VÖGEL, Herfried. Die Pluralisierung des Paratextes in der Frühen Neuzeit: Theorie, Formen, Funktionen. Berlim: Lit Verlag, 2008.

Marcos Machado Nunes - Doutor em Letras pela Universidade Federal do Rio Grande do Sul, é leitor de Língua Portuguesa na Ruhr-Universität Bochum, na Alemanha. Foi leitor brasileiro na Universidade Eötvös Loránd, de Budapeste, entre 2006 e 2010. É autor de Rio de Janeiro: eine literarische Einführung (2013), "Transformações da heroicidade épica em $A$ Independência do Brasil, de Teixeira e Sousa" (2014) e de "Anhangá. Curupira. Jurupari", entre outras publicações. É membro da equipe de pesquisadores do projeto Discurso da épica nas culturas lusófonas do século XIX - Probral Capes/DAAD 2018-2021. Orcid 0000-0001-84416668.

Submetido em 11/01/2020

Aceito em 22/03/2020 